\title{
IN-SITU EBSD OBSERVATIONS OF RECRYSTALLIZATION AND TEXTURE EVOLUTION IN ROLLED Mg-2Zn-xCe (wt.\%)
}

\author{
Ajith Chakkedath ${ }^{1}$, David Hernández Escobar ${ }^{2}$, Jan Bohlen ${ }^{3}$, Sangbong Yi ${ }^{3}$, Dietmar Letzig ${ }^{3}$, Carl Boehlert ${ }^{1,4}$ \\ ${ }^{1}$ Department of Chemical Engineering and Materials Science, Michigan State University, East Lansing, Michigan 48824-1226, USA \\ ${ }^{2}$ Technical University of Madrid, Calle Ramiro de Maeztu, 7, 28040 Madrid, Spain \\ ${ }^{3}$ Magnesium Innovation Centre MagIC, Helmholtz-Zentrum Geesthacht, Max-Planck-Str. 1, D-21502 Geesthacht, Germany \\ ${ }^{4}$ IMDEA Materials Institute, C/Eric Kandel 2, 28906-Getafe, Madrid, Spain
}

Introduction

Wrought magnesium $(\mathrm{Mg})$ alloys are attractive for automotive applications where light-weighting is critical. One of the major challenges with conventional $\mathrm{Mg}$ alloys, such as $\mathrm{Mg}$ $3 \mathrm{Al}-1 \mathrm{Zn}(\mathrm{wt} . \%)$, is the strong texture formation after rolling and subsequent annealing, which results in anisotropic mechanical properties and poor cold formability [1]. It was observed that relatively weak texture can be obtained by dilute rare-earth additions such as $\mathrm{Ce}$ [2]. However, the mechanisms responsible for the weak texture formation during annealing are not clear. The goal of this study was to investigate recrystallization and texture evolution during annealing in a Ce containing $\mathrm{Mg}$ alloy system using in-situ techniques.

\section{Experimental methods}

Mg-2Zn-0.2Ce(wt.\%) and Mg-2Zn-0.6Ce(wt.\%) alloy sheets, $\sim 1 \mathrm{~mm}$ thick, were studied in the as-rolled condition. For electron backscatter diffraction (EBSD) analysis, $\sim 10 \mathrm{~mm}$ wide and $\sim 15 \mathrm{~mm}$ long samples were cut from the sheet material using a diamond saw. One of the sample surfaces was mechanically polished and then electropolished using a mixture of 30\% Nitric acid and $70 \%$ Methanol as electrolyte. The electrolyte temperature was kept below $-25^{\circ} \mathrm{C}$ and a voltage of $\sim 12 \mathrm{~V}$ was used.

EBSD analysis was performed while the sample was kept at a desired temperature. The specimen was heated using a $6 \mathrm{~mm}$ diameter tungsten-based heating element placed beneath the sample. EBSD maps of the same area of $\sim 100 \mu \mathrm{m} \mathrm{x} \sim 125 \mu \mathrm{m}$ was collected at $25^{\circ} \mathrm{C}, 150^{\circ} \mathrm{C}, 200^{\circ} \mathrm{C}, 225^{\circ} \mathrm{C}, 250^{\circ} \mathrm{C}, 275^{\circ} \mathrm{C}, 300^{\circ} \mathrm{C}$, and $325^{\circ} \mathrm{C}$. Each scan took $\sim 45-55$ minutes at a $0.5 \mu \mathrm{m}$ stepsize. The specimen temperature was kept constant within $\pm 3^{\circ} \mathrm{C}$ during the scan. A thermocouple was spot welded to the sample surface to monitor the temperature.

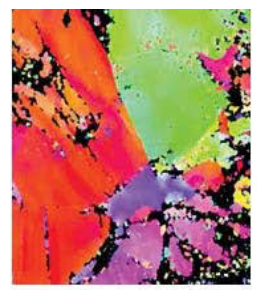

(a)

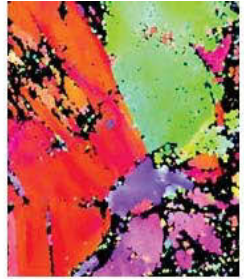

(b)

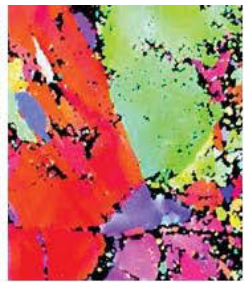

(c)

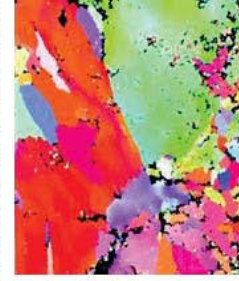

(d)

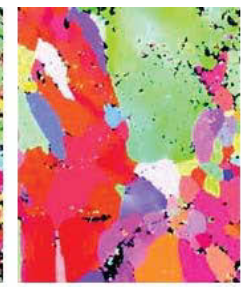

(e)

\section{Results}

Both as-rolled materials exhibited a basal texture in which the c-axis tends to align perpendicular to the rolling direction. The $\mathrm{Mg}-2 \mathrm{Zn}-0.2 \mathrm{Ce}($ wt.\%) sheet exhibited a stronger texture, with a maximum intensity of $\sim 10$ times random in 0001 pole figure along the normal direction (ND), compared to the Mg$2 \mathrm{Zn}-0.6 \mathrm{Ce}$ (wt.\%) sheet, which exhibited a maximum intensity of $\sim 5$ times random.

In $\mathrm{Mg}-2 \mathrm{Zn}-0.2 \mathrm{Ce}$ (wt.\%), new grains started to appear at $\sim 200^{\circ} \mathrm{C}$ (See Figure 1). At $\sim 300^{\circ} \mathrm{C}$, a completely recrystallized microstructure was formed. Grain boundaries with orientation relationships corresponding to $\{10 \overline{1} 2\}$ extension twinning $\left(86^{\circ}\right.$ about $<11 \overline{2} 0>),\{10 \overline{1} 1\}$ contraction twinning $\left(56^{\circ}\right.$ about $\left.<11 \overline{2} 0>\right)$, and $(10 \overline{1} 2)-(01 \overline{1} 2)$ extension double twin $\left(60^{\circ}\right.$ about $\left.<10 \overline{1} 0>\right)$ were observed. This was expected to be due to the recovery and growth of the twins formed during the rolling process. Among the misorientation relationships observed between the newly formed high angle grain boundaries, rotation axis about $\langle 10 \overline{1} 0\rangle,\langle 11 \overline{2} 0\rangle$, and $<10 \overline{1} 1>$ were the most prevalent. It is noted that rotation axes about other $<$ hki0 $>$ and $<$ hkil $>$ were also observed.

In the completely recrystallized microstructure, the fraction of high angle grain boundaries with a rotation axis about $<10 \overline{1} 0>,<11 \overline{2} 0>$, and $<10 \overline{1} 1>$ in $\mathrm{Mg}-2 \mathrm{Zn}-0.2 \mathrm{Ce}(\mathrm{wt} . \%)$ and $\mathrm{Mg}$ $2 \mathrm{Zn}-0.6 \mathrm{Ce}$ (wt.\%) were similar with $\sim 16 \%$ for each case. However, a significantly lower fraction $(\sim 6 \%)$ of grain boundaries with rotation axis about $<10 \overline{1} 1>$ was observed in Mg-3Al$1 \mathrm{Zn}($ wt.\%).

\section{References}

[1] Boehlert, C. J., et al. Acta Materialia 60.4 (2012): 1889-1904.

[2] Yi, Sangbong, et al. Acta Materialia 58.2 (2010): 592-605.

Figure 1. The EBSD IPF map in the normal direction of the same area analyzed for $\mathrm{Mg}-2 \mathrm{Zn}-0.2 \mathrm{Ce}\left(\right.$ wt. $\%$ ) captured at (a) $25^{\circ} \mathrm{C}(\mathrm{b}) 150^{\circ} \mathrm{C}$ (c) $200^{\circ} \mathrm{C}$ (d) $225^{\circ} \mathrm{C}$ (e) $250^{\circ} \mathrm{C}$ (f) $275^{\circ} \mathrm{C}$ (f) $300^{\circ} \mathrm{C}$ and (g) $325^{\circ} \mathrm{C}$. The rolling direction is horizontal. 